\title{
Improvement of the Level of Learners or "Abusive Results"?: A Survey of Gabon's Fourth-Year Primary School Teachers on the CBA Correction Grids
}

\author{
Jean-Aimé Pambou \\ École Normale Supérieure du Gabon \\ Jean Jacques Essono Eny \\ Direction de la Collation des Grades-DGEC
}

\begin{abstract}
In the context of frequent debates on the Competency-Based Approach in Gabon, we focused on primary school teachers, who are required to use this approach in their classrooms. Based on qualitative and quantitative approach, this work presents the results of a questionnaire on the use of rubrics for correcting written production in Grade 4. Essentially, almost all of the nineteen informants (18/19) acknowledged that the proposed rubrics now help in the practice of remediation activities, but several (15/19) also argued that they tend to promote "abusive results" in the evaluation of learners' writing. Inspired by both cognitivist and socio-constructivist theories, our contribution allows us to identify certain grievances against the CBA in Gabon and to formulate proposals to ensure that the problems of written production are better taken into account.
\end{abstract}

Keywords: $C B A$, correction grids, written production, errors, evaluation criteria

\section{INTRODUCTION}

The introduction of the Competency-Based Approach (CBA) and new processes for assessing student learning in the Gabonese education system has led to new pedagogical and evaluative practices among primary school teachers. Among the innovations resulting from this method, which has been tried out in Gabon since 2002, is the use of marking grids for the assessment of pupil learning in all subjects.

Since the generalization of the CBA in 2005, a few studies have been carried out, notably by student inspectors at the end of their training at the École normale supérieure. Some of this research has focused on the issue of the implementation of CBA by teachers (Dzobani, 2009). Others have dealt with remediation (Nguembi, 2006; Kalagnaga, 2012; Mapangou, 2016). The last cited author highlighted the importance of the marking grid on the assessment of grade 5 learners' writings containing errors. He showed the positive results of this approach with a sample of 273 learners from two private Catholic schools in Libreville, with the particularity that these errors were not those made by the learners themselves. Another work, that of Bivigou (2014), particularly drew our attention. The author was interested in the impact of the correction grid on school performance in the field of mathematics. He noted that the appropriation of the correction grid by the teacher and the students' improved performance. Therefore, the question for us was whether 
what is said about mathematics can be confirmed in the field of written French, by relying, in a precise manner, on the views of teaching practitioners.

To do this, we drew inspiration from a dissertation for the Certificate of aptitude for the primary inspectorate (Essono Eny, 2016). In this empirical research, fourth grade primary school teachers were asked whether, in their opinion, marking grids really help to catch errors in written production and whether they also guarantee an objective assessment. The present reflection includes the statement of the aim, the problem underlying it, the methodology, the analysis of the data and the presentation and discussion of the results.

\section{PURPOSE OF THE STUDY}

The purpose of this study is to report on what teachers think of the grading grids they have been using since the introduction of CBA in fourth grade in Gabon. With this in mind, the aim is to form an opinion on how informants judge the marking scales, but also to draw a few lessons from these assessment tools in use at primary level.

\section{PROBLEMATIC}

The introduction of correction grids in primary education in Gabon is the result of the recommendations of the Estates General of Education organised in 1983. The aim of these was to provide solutions to the problem of education in general, and elementary schooling in particular. Faced with high wastage and repetition rates, discussions were held with a view to improving practices relating to the evaluation of learning achievements, especially practices centred on formative evaluation.

In 1992, the Gabonese state drew up several projects to improve teachers' teaching practices and to take account of formative evaluation throughout learning and the exploitation of learners' mistakes. These various projects were made possible thanks to the Aid Fund for Cooperation and Support for the Development of Education in Gabon (AFC-SDEG) and the Support Program for the Gabonese School Education System (AFC-SPGSES). These successive projects in Gabon all developed an approach centred on the pedagogy of error as a means of improving assessment practice in all subjects. Despite their contribution, repetition and wastage rates remained very high.

In 2000, the UNESCO report on the Gabonese education system noted that $33 \%$ of pupils repeat their classes in that year, and 40\% reach the CM2 level (now grade 5). Accordingly, in correspondence No 000948/MEN/PPG/CAB of 17 April 2000, the Minister of Education instructed the National Pedagogical Institute (NPI) to review curricula, consider evaluation methods and ways of improving school results. The teacher's discourse, these guidelines stipulated, was to be reduced to the essentials, in favour of oral or written production and the correction of errors.

In 2002-2003, the European Development Fund (EDF) organised, at the NPI, days of reflection on the practice of evaluation taking into account the real difficulties of pupils. At the end of these meetings, a project to develop new curricula and new processes for assessing learning outcomes was set up. These processes are based on criterion-referenced assessment. In 2005, CBA was introduced at primary level. The adoption of this approach was materialised by the production of tools to support the reform (target situation notebooks, integration guides), because inclusive education regularly invites pupils to resolve situations that lead them to reinvest and integrate their learning by mobilising resources (knowledge, know-how, etc.). Each target situation is accompanied by a correction grid. However, despite these innovations, there is no evidence today to suggest that the level of fourth year primary school learners has changed, given the extent to which writing problems are found here and there in school writing. Hence our overall question put to the informants: do the CBA correction grids really enable us to pick up the written production errors of fourth grade pupils? If not, what should be considered for a better mastery of learners' written production? 


\section{THE CORRECTION GRID IN CBA}

Roegiers (2005, p. 120) defines the correction grid as "a tool for assessing a criterion through precise indicators". It is, in fact, an assessor's instrument that responds to the concern for standardisation of correction and contributes to supporting a judgement on the student's production. The CBA Correction Grids is an essential tool for the evaluation of competences, displaying criteria and recording the different types of expected answers. For each of these answers, it assigns a mark, according to the degree of achievement of the objective. In order to report on this, we have referred to the presentation given in the Guide d'intégration français $4^{\mathrm{e}}$ année (IPN, 2012). The example we present allows us to associate the correction grids with the corresponding situations. We have randomly chosen a problem situation, contained within a level. This choice is made to show the correlation between the problem-situation and the correction grid. The example is taken from Tier 1, page 32, of the Guide d'intégration français $4^{e}$ année.

\section{A Sportsman's Diet ${ }^{1}$}

A sportsman spends a lot of energy. What does he need for his diet? He needs a regular and sufficient supply of food to avoid undernutrition. A sportsman's diet must be balanced and varied. He must eat meat, fish, vegetables, fruit rich in vitamins, carbohydrates, fats, proteins, etc., in order to prevent malnutrition. Also, drinking water in sufficient quantity every day is useful to avoid dehydration in sportsmen and women.

To be in good health, we must therefore feed ourselves in this way.

FIGURE 1

\section{SPORTSMAN'S DIET}

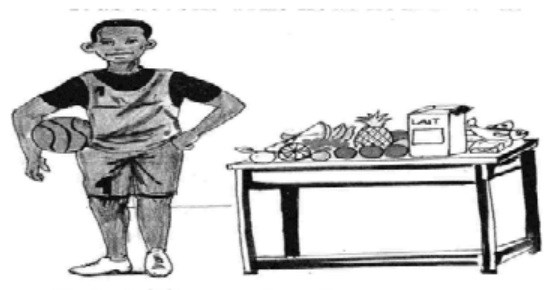

\section{Instructions:}

1. Read the text and fill in the following table:

\begin{tabular}{|l|l|}
\hline To avoid undernutrition & \\
\hline Why drink enough water? & \\
\hline What you should find in a balanced meal & \\
\hline
\end{tabular}

2. In the text, note the sentence that invites everyone to eat like a sportsman.

3. You and your friend decide one day to make a balanced meal. Write in at least six sentences what you choose as food and what you do to get the meal ready, using the present tense, declarative sentences and affirmative form.

\begin{tabular}{|l|l|l|l|l|}
\hline CB2P1S1 & C1 & C2 & C3 & C4 \\
\hline Q1 & $/ 1$ & $/ 1$ & $/ 1$ & $/ 1$ \\
\hline Q2 & $/ 1$ & $/ 1$ & $/ 1$ & \\
\hline Q3 & $/ 1$ & $/ 1$ & $/ 1$ & \\
\hline
\end{tabular}


TABLE 1

SITUATION CORRECTION GRID 1 CB2 P1

\begin{tabular}{|c|c|c|c|c|}
\hline Instructions & $\begin{array}{l}\mathrm{C} 1: \\
\text { Correct } \\
\text { interpretation } \\
\text { of the } \\
\text { situation }\end{array}$ & $\begin{array}{l}\mathrm{C} 2: \\
\text { Proper use of language } \\
\text { tools }\end{array}$ & $\begin{array}{l}\mathrm{C} 3: \\
\text { Consistency of } \\
\text { production }\end{array}$ & $\begin{array}{l}\text { C4 : } \\
\text { Presentation }\end{array}$ \\
\hline Q1 & $\begin{array}{l}1 \mathrm{pt} \text { if the } \\
\text { student fills in } \\
\text { the whole } \\
\text { table with the } \\
\text { information in } \\
\text { the text } \\
0.5 \mathrm{pt} \text { for two } \\
\text { filled lines }\end{array}$ & $\begin{array}{l}1 \mathrm{pt} \text { if the student fills in } \\
\text { the entire table with the } \\
\text { correct information } \\
\text { (sufficient food / to avoid } \\
\text { dehydration / meat, fish, } \\
\text { vegetables, fruit, etc.), even } \\
\text { with spelling mistakes } \\
0,5 \text { pt for two lines filled } \\
\text { even with errors (we } \\
\text { underline) }\end{array}$ & $\begin{array}{l}1 \mathrm{pt} \text { if the student fills in } \\
\text { the table with the right } \\
\text { information (sufficient } \\
\text { food/to avoid } \\
\text { dehydration/meat, fish, } \\
\text { vegetables, fruit, etc.) } \\
\text { without mistakes. } \\
0.5 \mathrm{pt} \text { for two correct } \\
\text { lines }\end{array}$ & \multirow{3}{*}{$\begin{array}{l}1 \mathrm{pt} \text { if the } \\
\text { student writes } \\
\text { without } \\
\text { erasures or } \\
\text { overwritten } \\
\text { text. }\end{array}$} \\
\hline Q2 & $\begin{array}{l}1 \mathrm{pt} \text { if the } \\
\text { student copies } \\
\text { a sentence } \\
\text { from the text }\end{array}$ & $\begin{array}{l}1 \mathrm{pt} \text { if the student copies } \\
\text { the right sentence (in order } \\
\text { to be healthy, we have to } \\
\text { feed ourselves this way), } \\
\text { even in error (we } \\
\text { underline) }\end{array}$ & $\begin{array}{l}1 \mathrm{pt} \text { if the student writes } \\
\text { the right sentence (to be } \\
\text { healthy, we need to feed } \\
\text { ourselves this way), } \\
\text { without mistakes }\end{array}$ & \\
\hline Q3 & $\begin{array}{l}1 \mathrm{pt} \text { if the } \\
\text { student writes } \\
\text { sentences } \\
\text { related to food } \\
\text { and what he } \\
\text { or she does to } \\
\text { get a balanced } \\
\text { meal }\end{array}$ & $\begin{array}{l}1 \mathrm{pt} \text { if the student writes six } \\
\text { declarative and affirmative } \\
\text { sentences in the present } \\
\text { tense, at least two of which } \\
\text { must be free of verbal or } \\
\text { grammatical spelling errors } \\
\text { (emphasis added). } \\
0.5 \mathrm{pt} \text { for three declarative } \\
\text { and affirmative sentences }\end{array}$ & $\begin{array}{l}1 \mathrm{pt} \text { if the sentences are } \\
\text { well arranged and } \\
\text { relevant to the situation }\end{array}$ & \\
\hline Weighting & $/ 3$ & $/ 3$ & 13 & $/ 1$ \\
\hline Total & \multicolumn{4}{|c|}{10} \\
\hline
\end{tabular}

Source : NPI (2012), Guide d'intégration français $4^{e}$ année, p. 35

According to the configuration of this diagram, the correction grid for written production used in the CBA includes three minimum criteria with the same number of points (3pts) and a refinement criterion with a value of one (1) point. The minimum criteria are the set of criteria on the basis of which success or failure is certified. They include: "Correct interpretation of the situation" or understanding of work instructions (Criterion 1), "Correct use of language tools" or respect for linguistic competence (Criterion 2) and "Consistency of production" or making statements without internal contradictions (Criterion 3). Presentation" (Criterion 4) is concerned with the presence or absence of erasures and overwriting in learners' writings.

On reading this table, it appears that each minimum criterion is assessed according to the precise instructions established in relation to the questions that learners must answer. However, when examined, these guidelines cover a wide range of aspects. Thus, for the criterion "Correct interpretation of the situation", we find both the element relating to "correct information" or the relevance between the choice of sentences in the text and the content of the information to be given, but also elements relating to "filling in the lines" and "copying sentences". As for the criterion "Correct use of language tools", it includes "filling 
the table with relevant information" - which may lead to the choice of vocabulary - "filling in the lines even with errors", tolerance of errors, production of declarative and affirmative sentences. For its part, the criterion "Consistency of production" also includes filling the table with correct information, tolerance of errors, recopying of sentences and the link between the sentences produced and the situation. Beyond these observations, the weighting is balanced between the three minimum criteria, which clearly means that they are mutually valid.

In short, with the exception of the "Presentation" criterion, which focuses solely on the question of erasures and overwriting, the other criteria deal with questions of several kinds. These include concerns relating to linguistic competence such as, here, "correct information"; the correlation between "the choice of sentences and the content of the information to be given"; the "filling in the table with relevant information"; the "production of sentences of a declarative and affirmative type" or the link between the sentences produced and the extralinguistic situation. To this can be added questions relating to other competences such as "filling in the lines", "filling in the table", "copying sentences", "relating the chosen sentences to the content of the information". Furthermore, one cannot overlook the "tolerance of errors" in some cases - and not the taking into account of the error - although this seems to weaken the idea of improving the quality of expression.

\section{FRAME OF REFERENCE}

The frame of reference adopted is constructivism which, as Astolfi (1997) states, does not to eliminate the learner's error, but to give it a positive status, insofar as this error makes it possible to better identify the difficulties encountered in the learning process in order to propose appropriate remedial action. This constructivist theory advocates that errors should be taken into account by the teacher when correcting them. It is from this perspective that we agree with Allal (1999) that assessment instruments, whether aptitude tests or tests used in the school system, are usually designed to provide a static measure of the state of abilities, knowledge or skills attained at a given point in time by the learner.

\section{METHODOLOGY}

We opted for a qualitative survey based on a questionnaire. The questionnaire is defined by Cuq (2003, p. 211) as an instrument that "allows for the systematic collection of empirical data and thus confirms the validity of the hypotheses formulated". We looked at some thirty teachers in the fourth year of primary school, from five schools in the school district of the municipality of Libreville-Nord ${ }^{2}$, during the period from 11 to 19 April 2016, when a strike was taking place in the education sector. Each informant had two days to fill in the questionnaire freely, without being influenced or pressured by the interviewer. We then had to go back to the informants to collect the completed forms. All we had to do then was to gather together all the points of view we had written down so that we could extract elements from them to answer our questions, taking into account the recurrence of certain facts and the originality of certain others, even if we had to reproduce them to the letter, if necessary.

However, it should be noted that out of these thirty or so teachers, only nineteen (19) returned the completed questionnaires. As for the others, they either returned the forms after the deadline, or refused to participate in this survey, precisely to protest against the unavailability, dating from 2014 (i.e. two years at the date of the survey), of support materials for the CBA method in schools.

Our questionnaire consists of two closed-ended questions, six open-ended questions and two scales. The two closed questions are as follows: Question 1: Have you received training on CBA? Question 2: Do you carry out remediation after marking students' papers? As for the six open questions, they are formulated as follows: Question 3: Do you use the problem-situation correction grids from the integration week? If so, which ones? If not, why not? Question 4: Do you think that the "correction grid" makes it easier to pick up mistakes? If yes, give an example. Question 5: What types of errors do you observe in your students' written productions? Question 6: Have you noticed a difference in students' performance in written production since the introduction of CBA? If so, on what aspect? Question 7: Do you observe a 
change in your role as a teacher since the introduction of CBA in your correction of written production? Give reasons for your answer. Question 8: If you were given the opportunity to change the marking grid, which aspect would you insist on? Finally, for both scales we have the following statements: Question 9: According to you, the use of the "correction grid" in written production is: very easy; fairly easy; easy; difficult; very difficult. Question 10: On a scale of 1 to 5, rate your mastery of the "correction grid for written production".

\section{SURVEY RESULTS}

Question 1: Have you received any training on CBA? The results of this question show that all informants have received training on CBA and the new evaluation processes. This assumes that all the informants selected are familiar with the CBA and the new evaluation processes when it comes to the related rubrics. It also assumes that teachers are empowered to answer questions about the marking scheme.

Question 2: Do you perform remediation after marking students' papers? The answer to this question is affirmative for eighteen (18) teachers and negative for only one. By accrediting this result, it can be estimated that many of the concerns of the NPI, Gabon's education regulatory body, are taken into account by the teaching profession. Thus, the innovations desired by the supervisory authority with regard to learner errors seem to have already taken shape in this area.

Question 3: Do you use the problem situation correction grids from the integration week? If yes, which ones? And if not, why not? In this respect, all the teachers answered in the affirmative and indicated as tools the integration guides where the different correction grids are recorded, namely: the Guide d'intégration de français, the Guide d'intégration de mathématique and the Guide d'intégration d'éveil. This suggests that the concrete use of marking grids is rooted in primary school teaching practices.

Question 4: Do you think that the "correction grid" makes it easier to pick up errors? If so, please give an example. Here, the majority of teachers (12), i.e. $63.15 \%$, answered no, compared to seven (7) teachers, i.e. a percentage of $36.84 \%$. Why then such a high percentage of negative answers when, in the previous question, almost all the informants stated that they were carrying out the remediation (of errors) favoured by the correction grids? The reason put forward is that the wording of the criteria "does not take into account the level of education". For the interviewees, this formulation is made in terms deemed "technical", such as criteria 2 "Correct use of language tools" and 3 "Consistency of production". The consequence that can be drawn from this is the following: if the teachers say that they carry out remediation, this is, in reality, done randomly, since they admit not understanding the proposed "technical" criteria. This amounts to asking oneself in advance about the real level - not of the learners - but of the teachers who must "handle" these grids for the benefit of their students.

Furthermore, given that, even with errors (cf. Criterion 2 in the table above), learners can validate points, it may be thought that this is the reason why many argue that the "correction grid" does not encourage the sampling of errors.

Question 5: What types of errors do you observe in your students written productions? Teachers unanimously cite spelling, grammar and conjugation errors as recurrent. In addition to these errors, the teachers mention respect for instructions, logical connectors, errors related to numbers (singular/plural), overgeneralisation $^{3}$, poor vocabulary, punctuation. In this sense, there is nothing really original in comparison with the current work on the analysis of errors in French. In other words, any audience of French-speaking learners can be confronted with the same writing difficulties.

Question 6: Have you noticed a difference in students' performance in written production since the introduction of CBA? If so, on what aspect? Here, the results are mixed. Ten (10) teachers, as opposed to nine (9), indicate a substantial improvement in written production results. The main argument put forward is that the grading grids make it very easy for students to get points, even if errors remain in the essays. For example, they believe that these grids promote "free point allocation that reflects 'undue achievement' or 'deception'".

Question 7: Do you notice any change in the way you correct students papers? Justify your answer. Twelve teachers (63.15\%) answered in the affirmative, compared with seven (36.84\%). They justify this 
change by the fact that the marking grid provides benchmarks for correction and allows for objective assessment, especially in mathematics, understandably. In accrediting these responses, we can see that the "correction grids" would certainly be more relevant in mathematics than in French, but that they nevertheless constitute important "benchmarks" for improving the practice of correction in French.

Question 8: If you were given the possibility to modify the correction grid, which aspect would you insist on, between the criteria and the indicators of other personal aspects to be formulated? Fifteen (15) teachers, i.e. a percentage of $78.94 \%$, specify the modification of the criteria, while three (3), i.e. $15.78 \%$, think that the correction indicators should be reviewed, while one (1), i.e. $5.26 \%$, expresses no opinion on this subject.

Question 9: In your opinion, is the use of the correction grid in written production: very easy; fairly easy; easy; difficult; very difficult? While no one finds these grids "very difficult" to use, twelve (12) teachers, i.e. a percentage of $63.15 \%$, consider them "difficult" to use. The remaining seven (7) are divided between those who find them "very easy" (three teachers, or $15.78 \%$ ); "fairly easy" (three teachers also or $15.78 \%$ ), and only one (5.26\%) who finds them "easy". This very high percentage of those who find the scales "difficult to use" may be explained by the diffuse nature of the elements to be taken into account in the marking scale, particularly in criterion 2 , but also by the difficulty they have in interpreting or understanding the wording of criteria 2 and 3 of the scale.

Question 10: On a scale of 1 to 5, rate your mastery of the "correction grid for written production". The results make it possible to make a clear distinction between, on the one hand, those who feel they have mastered the correction grid and, on the other hand, those who do not master it or who have an average mastery of it. In the first group we have six teachers. Of these, three (3), i.e. $15.78 \%$, are at level 5, that of perfect mastery, and three (3) others are at level 4, that of good mastery. In the second group, there are a total of thirteen (13) informants. Here, one (1) teacher (i.e. 5.26\%) is at level 1, which represents no mastery of the grids; another is at level 3, that of average mastery, while the largest number - eleven (11), the equivalent of $57.9 \%$ - is at level 2 or approximate mastery of the grids. In short, it appears, for the most part, that only a minority (approximately $31.56 \%$ ) of informants consider themselves to have mastered the correction grids, while the largest number (68.44\%) have an approximate or insufficient mastery of them, or even very insufficient mastery.

\section{DISCUSSION}

The discussion, following these results, consists of saying whether, finally, for our informants, the correction grids used in CBA favour the sampling of errors and, if so, what, if anything, should be envisaged, to take better account of the real difficulties of 4th year primary school learners. To this end, it is important to highlight teachers' main grievances against the correction grids. These grievances concern the relevance of the constituent elements of criterion 2 ("Correct use of language tools"), the difficulties in interpreting criterion 3 ("Consistency of production") and the "abusive results" pointed out by the speakers. In addition, it is useful to note the main suggestions made by the informants on the topic under discussion.

The grievance on the "correct use of the tools of the language" relates to the fact that this single criterion would encompass vocabulary, conjugation, grammar and different spellings. It is through this criterion that the teacher verifies "respect for the norms of the French language". However, according to the informants, the written language is still under construction among 4th year primary students. Therefore, they do not

consider it appropriate to combine all the language tools in a single criterion because the linguistic difficulties differ from one student to another, they add. Among the proposals recorded, some put forward the idea of replacing the criterion "correct use of language tools" with that of "mastery of spelling". Only different phonetic, lexical, grammatical and verbal spellings would then be taken into account in this configuration. In short, this would mean focusing only on language skills, according to an 'old' conception of language teaching, which would be reminiscent, not of the CBA, but of the Objective-Based Approaches (OBA).

The difficulty in interpreting the criterion of coherence of production is based on the following questions formulated by teachers themselves: "To what extent can a text produced by a 4th year primary 
school student be said to be coherent? "To what extent can the markers of coherence of a text be identified and how can we determine whether they have been used appropriately?". These are all questions that leave teachers perplexed in their judgements. With regard to the last question raised here, it could be objected that if the coherence of production can correspond to the absence of internal contradictions in statements (cf. supra, 1st paragraph of the commentary on the table), then it is quite possible to isolate elements such as semantic incompatibilities between words, or even the relevance or otherwise of certain linking words in learners' statements. Unless it is absolutely necessary to cite aspect by aspect all the specific elements to be noted in the grids!

Observation of all the responses collected in our questionnaire reveals, in the end, a certain "uneasiness" in the use of the correction grids among teachers. This discomfort is explained by the fact that, for them, the criteria are not formulated clearly, but in terms that are too "technical". They therefore propose the following tripartition of minimum criteria as "simple" or "non-technical" terms: 1/ "Interpretation of the situation"; 2/ "Mastery of spelling"; 3/ "Sentence construction". This "malaise" is further corroborated by the fact that $68.44 \%$ of teachers admit to not mastering the correction grids. Furthermore, other informants castigated the excessive diversity of skills to be assessed. For example, with regard to the criterion 'Use of language tools', some recommend focusing on morphology, grouping together 'errors arising from variations in form'. In addition, one aspect horrifies teachers: the fact of validating points on written productions "full of errors". One can then understand why, according to them, the current state of the CBA correction grids "does not help to pick out the various errors" from the learners. On this last point, it seems that teachers have not sufficiently appropriated the philosophy of the CBA and, overall, the philosophy of communicative approaches to language teaching.

\section{CONCLUSION}

The work we carried out consisted of giving the floor (or the pen) to 4th grade primary school teachers in order to get their opinion on the correction grids used in CBA. While we wanted to involve at least thirty informants, the context of the teachers' strike forced us to work with only nineteen teachers from five schools in the northern district of Libreville. Although they all say they have all undergone CBA training, the judgements they make on the correction grids under this approach, which has been generalised in Gabon since 2005, are not encouraging. Essentially, the informants say, on the one hand, that the grids are not formulated in simple language and are therefore not easy to interpret; that they include too many skills to be acquired and that they do not encourage the sampling of errors, with a view to better remediation; and on the other hand, that these same grids tend to encourage 'abusive results', in that students can have high or good marks, even when the copies are full of errors.

How, then, can such negative evaluation be understood? One way is that although the CBA is still considered an innovation in the Gabonese education system, it is obvious that it cannot function properly in a school context often marked by repeated strikes and known for its multifaceted dysfunctions. Moreover, even if teaching staff have been trained in this approach, it would not be superfluous to continue to maintain the people concerned in in-service training workshops, retraining programmes or seminars on the foundations, issues and functioning of the reform. This is all the more true since, in the informants' responses, some interventions sometimes made us perceive nostalgia for "old" pedagogical practices. Moreover, on closer inspection, language competence, in these correction grids, is the only one that seems to be of real concern to teachers.

Although this negative assessment by practitioners in the field cannot necessarily be generalised to the entire teaching profession in Gabon, it may nevertheless be of concern to the country's educational and institutional decision-makers. Thus, we believe that a more systematic or more global assessment carried out at the level of the Republic should be carried out on the CBA, not for the principle of a "new foundation" on the issue, nor for the principle of good research to be put away "in the drawers of museums", but in order to be able to draw the main consequences and, no doubt, to better support teachers in this methodological approach which is increasingly widespread in education systems internationally. 


\section{ACKNOWLEDGEMENT}

Translated \& edited by American Publishing Services (https://americanpublishingservices.com/).

\section{ENDNOTES}

1. Situation 1 of CB2 of Tier 1 from the Guide d'intégration français (NPI, $2012: 32$ )

2. These are the following public schools: Alibandeng, Charbonnages, ENS A, ENSET A and ENSET B

3. For Cuq (2003 P. 230), overgeneration designates "the acquisition procedure which consists in applying too generally a rule discovered for one or more language functions and results in a non-conforming interlanguage".

\section{REFERENCES}

Allal, L. (1999). Acquisition and évaluation des compétences en situation scolaires. In J. Dolz \& Ollagnier (Eds.), L'énigme de la compétence en éducation (pp. 77-94). Bruxelles : De Boeck.

Astolfi, J-P. (1997). L'erreur un outil pour enseigner. Paris: ESF éditeur.

Bivigou, C. (2014). Impact de la grille de correction sur les performances scolaires: Cas des écoles publiques de la circonscription scolaire de Libreville-Sud, Mémoire pour l'obtention du CAIP. Libreville: ENS, inédit.

Cuq, J-P. (Dir). (2003). Dictionnaire de didactique du français langue étrangère et seconde. Paris: Clé international/Asdifle.

Dzobani, A. (2009). Problématique de la mise en ouvre de l'approche par les compétences de base. Mémoire pour l'obtention du CAIP. Libreville: ENS, inédit.

Essono Eny, J.J. (2016). Les grilles de correction de la production écrite utilisées dans l'APC en $4^{e}$ année primaire: Enquête, analyse et propositions. Mémoire pour l'obtention du CAIP. Libreville: ENS, inédit.

I.P.N. (2012). Guide d'intégration français 4 è année. Libreville: EDIG.

Kalagnaga, F. (2012). La pratique de la remédiation à l'école élémentaire 5 ans après la généralisation de l'Approche par les compétences de base: Bilan et perspectives. Mémoire en vue de l'obtention $d u$ CAIP. Libreville: ENS, inédit.

Mapangou, A. (2016). Les erreurs orthographiques en $5^{e}$ année primaire: La grille de correction comme outil de remédiation. Mémoire en vue de l'obtention du Certificat d'aptitude au professorat de l'enseignement normal. Libreville: ENS, inédit.

Nguembi, F. (2006). Impact de la remédiation sur les performances des élèves. Mémoire en vue de l'obtention du CAIP. Libreville: ENS, inédit.

Roegiers, X. (2005). L'évaluation selon la pédagogie de l'intégration: Est-il possible d'évaluer les compétences des élèves? In K. Toualbi-Thaâlibi \& S. Tawil (Dir.), La refonte de la pédagogie en Algérie. Défis et enjeux d'une société en mutation (pp. 107-124). Alger: UNESCO-ONPS. 